\title{
A Survey on AAC Fringe Vocabulary to Support Personal Assistance Service
}

\author{
Daeun Park ${ }^{\mathrm{a}}$, Sangeun Shin ${ }^{\mathrm{b}}$ \\ ${ }^{a}$ Graduate Program in Speech-Language Pathology, Chungnam National University, Daejeon, Korea \\ ${ }^{b}$ Department of Speech-Language Pathology, Chungnam National University, Daejeon, Korea
}

Correspondence: Sangeun Shin, $\mathrm{PhD}$ Department of Speech-Language Pathology, Chungnam National University, 99 Daehak-ro, Yuseong-gu, Daejeon 34134, Korea Tel: +82-42-821-6392

Fax: +82-42-823-3667

E-mail: sashin@cnu.ac.kr

Received: October 5, 2021

Revised: November 23, 2021

Accepted: December 2, 2021

This paper was revised and supplemented part of the Master's thesis of the first author (2021).
Objectives: There are increasing demands for personal assistance services which help the disabled to carry out their daily life. To use augmentative and alternative communication (AAC) approaches more effectively in daily communication, it is essential to include the appropriate core and fringe vocabulary in the $\mathrm{AAC}$ system. Considering the fact that there are few studies in Korea which have reported fringe vocabulary compared to core vocabulary, this study is aimed to develop a noun list that can be used to promote interactive communication between the disabled and their assistants in each communication situation. Methods: A literature review was conducted to elicit frequently used nouns in each communication situation. Then, a survey was carried out to identify nouns with high word commonality across 105 personal assistants. Results: Sixty-three nouns with more than $50 \%$ of word commonality across personal assistants were identified from the 244 fringe vocabulary; consisting of 112 nouns in the area of going out, 29 in cleaning, 27 in personal hygiene, 26 in cooking, 20 in meal supporting, 20 in other service areas, and 10 in commuting. Conclusion: The identified nouns are expected to help people with complex communication needs to express their needs and wants more clearly and effectively using those nouns embedded in their AAC systems. The list of nouns can be used not only for people who receive personal assistance services, but also for people who rely on AAC systems to express their daily needs.

Keywords: Augmentative and alternative communication (AAC), Fringe vocabulary, Noun, Personal assistance service, Word commonality
장애인 활동지원서비스란 장애인이 신체적 또는 정신적 불편함 으로 일상생활을 영위할 수 없는 부분을 활동지원사의 도움으로 원활히 수행할 수 있도록 지원하는 서비스를 말한다(Ministry of Health and Welfare, 2019). 활동지원서비스를 이용하는 장애인의 수는 2014년 이용자 수 53,952명에서 2018년 78,202명으로 연평균 9.7\% 증가하였으며(Ministry of Health and Welfare, 2019) 하루 평 균 4.7시간(하루 중 $19.7 \%$ )을 이용하는 것으로 나타났다(Hwang, 2014).

장애인이 효과적으로 활동지원서비스를 받기 위해서는 활동지 원사와의 원활한 의사소통이 필수적이다(Song \& Jeong, 2009). 그 러나 복합적인 의사소통 요구(complex communication need, $\mathrm{CCN}$ )를 지닌 이들 장애인은 전형적인 의사소통 방식인 구어나 문
어로 소통하는 데에 큰 어려움이 있기 때문에 타인과의 상호작용 과 사회 참여에 큰 제한을 받을 수 있다(Beukelman \& Miranda, 2013; Fried-Oken \& Granlund, 2012). 몇몇 연구에서는 활동지원 사와 장애인 이용자 간의 의사소통 문제를 보고한 바 있는데, 활동 지원사가 장애인과 소통하는 방법에 대한 지식이 부족하여 상호작 용이 안되는 경우(Choi \& Kim, 2016)가 있으며, 장애인에게 의사 를 묻지 않고 활동지원사가 추측하여 부정확하게 또는 불필요하게 서비스를 제공하는 사례도 보고되었다(Im, 2018). 대개 의사소통 단절이 발생하는 경우는 장애인 이용자가 원하는 것을 활동지원사 가 파악하기 힘든 때인 것으로 나타났다(Jeong, 2018). 장애 유형별 로 보고된 연구는 자폐스펙트럼 장애 이용자에 관한 연구가 유일 하였는데(Jeon \& Hwang, 2017), 활동지원사와 이용자 간의 의사소 
통 문제는 장애인의 의사소통 방식이 중증도에 따라 달라져서 이 에 대처하기 어려운 상황, 장애인 이용자가 위험한 행동을 하는 상 황, 그리고 이용자와 활동지원사 간에 양방향적 의사소통이 원활 하지 않은 경우에 발생하는 것으로 보고되었다. 마지막으로 장애인 이용자가 활동지원서비스를 이용하면서 자신의 욕구를 온전히 표 현할 수 있는 의사소통기술이 부족하거나 활동지원사와의 관계 악 화를 걱정하여 소극적인 태도로 의사소통 하게 되는 것도 원활한 의사소통을 제한하는 요인으로 보고 있다(Kim, 2012).

이러한 의사소통의 불협화음을 줄이고 장애인 이용자가 활동지 원사와의 소통에 적극적으로 참여하고 필요와 요구를 달성할 수 있도록 하기 위해서는 보완대체의사소통(Augmentative and Alternative Communication, $\mathrm{AAC}$ )이 효과적인 대안이 될 수 있다. $\mathrm{AAC}$ 란 구어와 문어의 의사소통 방식을 포함하여 언어와 말의 표 현 및 이해에 치명적인 장애를 지닌 사람들의 일시적 또는 영구적 손상, 활동 제한, 참여 제약 등을 연구하고 이를 보완하는 시도들 을 말한다(ASHA, 2005). 활동지원사와 이용자가 AAC를 이용하 며 효과적으로 의사소통 하기 위해서는 장애인 이용자가 자신의 요구나 바람을 정확하게 표현할 수 있는 활동지원서비스 상황 별 주요 어휘를 선정하고 이를 그들의 $\mathrm{AAC}$ 체계에 반영할 수 있어야 한다. 더욱이 제공서비스 상황에서는 장애인 이용자가 활동지원사 에게 자신의 요구를 정확하고 신속하게 표현해야 할 필요성이 있으 므로 다른 사람의 행동에 영향을 줄수 있는 지시적 기능을 지는 명 사(Croft, 2000)에 중점을 둔 어휘 연구가 필요하다.

어휘는 크게 핵심어휘와 부수어휘로 구분할 수 있는데, 핵심어 휘란 의사소통 시 빈번하게 나타나고 많은 사람들에게 공통적으 로 출현하는 고빈도 어휘를 말하며, 대부분 대명사, 조동사, 전치사, 접속사 등이 포함된 기능어(functional word)가 이 어휘군에 포함 되어 있는 것으로 보고되고 있다(Banajee, Dicarlo, \& Stricklin,

2003; Beukelman, Jones, \& Rowan, 1989; Kim, Park, \& Min, 2003). 전체 발화의 약 78-85\%의 비율을 차지하며(Baladin \& Iacono, 1999; Beukelman et al., 1989; Hill, 2001) 의사소통 환경, 연령과 관 계없이 나타나는 특징을 보인다(Banajee et al., 2003; Hill, 2001). 핵 심어휘는 보통 1,000 단어 당 .5 회 이상 출현 빈도율을 기준으로 정 의하거나 빈도순위, 빈도율, 어휘공통성 점수 등을 개별적으로 사 용하거나 조합하여 설정해 놓은 기준치 이상의 빈도순위로 정의하 기도 한다(Balandin \& Iacono, 1999; Beukelman et al., 1989; Marvin, Beukelman, \& Bilyeu, 1994; Shin \& Hill, 2016; Trembath, Balandin, \& Togher, 2007). 이와는 달리 부수어휘는 개별적이고 특정 상황이나 환경에서만 주로 사용되는 명사, 형용사, 동사, 부사 등의 내용어(content word) 중심의 어휘를 말하는 것으로(Marvin et al., 1994; Trembath et al., 2007) 특정 주제에 대한 필수적인 정보 를 전달하는 역할을 하며 핵심어휘에 나타나지 않은 개인이 필요 로 하는 구체적인 생각, 메시지 표현을 나타낼 수 있다(Baladin \& Iacono, 1998). 부수어휘는 핵심어휘의 선정방법에 따라 결정되며 보통 1,000 단어 당 .5 회 미만으로 출현된 나머지 어휘로 정의되는 경우가 많다(Balandin \& Iacono, 1999; Lee, Kim, \& Park, 2005; Park \& Kim, 2015).

국내에서는 이미 다양한 연령대와 장애인 및 비장애인을 대상으 로 핵심어휘 연구가 진행되었으며(Shin \& Park, 2020), 이는 상대적 으로 적은 어휘로 여러 활동서비스 상황에서 사용될 수 있을 것으 로 사료된다. 다만, 활동지원서비스가 지닌 다양한 상황들은 이용 자 개개인의 요구와 필요를 달라지게 할 수 있으므로 의사소통 판 에 탑재되는 어휘는 환경별 특징을 고려하여 다르게 반영되어야 하 며(Balandin \& Iacono, 1998; Beukelman \& Miranda, 2013; Yorkston, Honsinger, Dowden, \& Marriner, 1989) 사용될 단어를 사전에 조사하여 이용자가 사용할 수 있는 환경을 만들어줄 필요 성이 있다(Park \& Kim, 2015).

그러나 국내외 AAC 어휘연구는 그 중요성 때문에 핵심어휘에 많이 집중된 편이기 때문에(Balandin \& Iacono, 1999; Beukelman et al., 1989; Kim et al., 2003; Kim \& Han, 2016; Lee et al., 2005; Marvin et al., 1994; Oh, Nam, \& Kim, 2014; Park \& Kim, 2015; Shin, 2017; Shin \& Park, 2020; Song, Song, \& Park, 2015) 상대적으 로 상황별로 필요한 부수어휘에 대한 연구가 덜 이루어진 편이다. 더욱이 각각의 활동지원서비스 상황에서 장애인 대상자와 활동지 원사 간의 원활한 의사소통을 위해 필요한 부수어휘에 대해서는 현재까지 연구가 이뤄지지 않아 이에 대한 연구가 필요하다.

이에 본 연구에서는 증가하는 활동지원서비스의 수요에 맞춰 장 애인과 활동지원사 간의 원활한 의사소통을 도모하기 위해 지원서 비스 영역별로 필요한 부수어휘를 문헌과 설문조사를 통해 살펴보 고자 하였다. 활동지원사를 설문 대상으로 한 이유는 직접 설문에 응하기 어려운 의사소통 장애인을 대신하여 이들의 활동을 밀착 지원하면서 보편적인 요구와 필요를 어느 정도 파악하고 있는 장애 인활동지원사의 의견이 반영될 필요가 있다고 보았기 때문이다. 아 울러 부수어휘에 초점을 맞춘 이유는 고빈도 핵심어휘에 대한 국내 외 선행연구 결과가 부수어휘보다는 상대적으로 많이 누적되어 있 다는 연구 현황에 기인한다(Banajee et al., 2003; Balandin \& Iacono, 1999; Beukelman et al., 1989; Boenisch \& Soto, 2015; Clendon \& Erickson, 2008; Deckers, Van Zaalen, Van Balkom, \& Verhoeven, 2017; Laubscher \& Light, 2020; Liu \& Sloane, 2006; Robillard, Mayer-Crittenden, Minor-Corriveau, \& Belanger, 2014; Shin 
\& Hilll, 2016; Shin, Park, \& Hill, 2021; Snodgrass, Stoner, \& Angell, 2013; Stuart, Beukelman, \& King, 1997; Trembath et al., 2007; Wood, Appleget, \& Hart, 2016). 본 연구에서는 특히 부수어휘의 대부분을 차지하면서(Marvin et al., 1994; Robillard et al., 2014; Shin et al., 2021), 지시적 기능을 지는 명사(Croft, 2000)에 초점을 두고 있다. 수집된 명사는 선행연구에서 보고하는 핵심어휘 목록 과 추후 통합하여 의사소통판에 반영함으로써, 장애인들이 상황 에 걸쳐 또는 각 상황마다 효과적으로 자신의 요구와 필요를 전달 하는 데 활용될 수 있을 것이다.

연구질문은 다음과 같다.

첫째, 지원서비스의 영역에 따라 활동지원사들이 보고한 어휘공 통성 백분율에 유의한 차이가 있는가?

둘째, 지원서비스의 영역별로 활동지원사간의 어휘공통성 백분 율이 $50 \%$ 이상인 어휘는 무엇인가?

셋째, 활동지원사가 지원서비스의 영역별로 필요하다고 응답한 추가 어휘는 무엇인가?

\section{연구방법}

\section{문헌 기반 어휘 분석}

RISS, KISS, DBpia, KCI, 스콜라의 데이터베이스에서 검색어 '어 휘(vocabulary)', '활동지원사(personal assistant)', 보완대체의사소 통(AAC), '명사(noun)'를 단일 또는 조합하여 1996년부터 2020년 상반기까지 발행된 문헌을 조사하였고 연구자와 언어병리학 박사 학위를 지닌 제 2 연구자의 검토를 통해 본 연구목적에 부합하는 문 헌 11개를 최종 선정하였다(Table 1).

수집한 어휘/메시지는 Ministry of Health and Welfare (2019)에
서 제시한 활동지원서비스의 10 개 영역에 따라 분류하였다(Appendix 1). 활동지원서비스는 크게 신체활동지원, 가사활동지원, 사회활동지원, 그 밖의 제공 서비스로 구성되어 있으며 세부 영역 으로 소분할 경우, 개인위생관리, 신체 유지 및 증진, 식사 도움, 실 내이동 도움, 청소 및 주변 정돈, 세탁, 취사, 등하교 및 출퇴근, 외출 시 동행, 그 밖의 제공 서비스 영역을 포함하게 된다. 여기서 그 밖의 제공 서비스 영역은 Ministry of Health and Welfare (2019)의 구분 기준에 따라 수급자 장애인의 취학 전 자녀의 양육 보조와 장애인 의 생활상의 문제 상담, 의사소통 도움, 그리고 위에 열거되지 않은 서비스 영역을 포함하는 것으로 하였다.

문헌에서 낱말 단위가 아닌 구/문장 단위의 메시지 목록을 제시 하는 경우에는 낱말 단위가 단어 조합을 통해 다양한 메시지를 생 성하는 유연성이 높다는 점을 고려하여(Stuart, Lasker, \& Beukel$\operatorname{man}, 2000)$, 낱말 단위로 분리하였고 내용어(content word)에 속하 는 명사어휘를 분석에 포함하였다.

어휘의 분류 작업은 제 1 연구자가 1 차로 실시한 후 제 2 연구자가 재 검토하여 완료하였다. 그 결과 개인위생관리 140 개, 신체 유지 및 증 진 2 개, 식사 도움 126 개, 실내이동 도움 8 개, 청소 및 주변 정돈 137 개, 세탁 0 개, 취사 109 개, 등하교 및 출퇴근 100 개, 외출 시 동행 820 개, 그 밖의 제공 서비스 180 개로 총 1,622 개의 어휘가 확인되었다.

특정 문헌의 어휘 편향성을 배제하기 위해 2개 이상의 문헌에서 보고한 어휘를 지원서비스의 영역별로 선별한 결과 개인위생관리 영역에서 27 개, 식사도움 20 개, 청소 및 주변정돈 29개, 취사 26개, 등하교 및 출퇴근 지원 10 개, 외출 시 동행 112 개, 그 밖의 제공 서비 스 20 개로 전체 10 개 중 7 개의 서비스 영역에 대해 총 244 개 어휘가 확인되었다.

Table 1. Data extracted from the 11 studies by literature review

\begin{tabular}{lllr}
\hline$\#$ & \multicolumn{1}{c}{ Study } & \multicolumn{1}{c}{ Vocabulary list in the study } & NTW \\
\hline 1 & Pae \& Kwak (2011) & Vocabularies list in the Korean version of M-B CDI & 641 \\
2 & Kim, Kim, \& Kim (2019) & Vocabulary list developed for deaf-blindness communication & 183 \\
3 & Kim \& Yeon (2019) & Vocabulary list in residential community situations for people with physical disabilities & 86 \\
4 & Moon (2011) & Vocabulary list developed for TOPIK. & 2,381 \\
5 & Moon \& Hwang (2015) & Vocabulary for elderly people & 27 \\
6 & Park (1999) & Vocabulary for students with intellectual disability & 638 \\
7 & Park (1996) & Vocabulary for nonspeaking children with disabilities surveyed by parents and teachers & 149 \\
8 & Lee \& Park (2000) & Vocabulary for children with communication disabilities surveyed by parents and teachers & 477 \\
9 & Lee, Pyun, \& Kwak (2011) & Vocabulary list as educational materials for children with developmental disabilities & 232 \\
10 & Chang, Jeon, \& Kim (2013) & Vocabulary list for elementary school students & 577 \\
11 & Ji (2018) & Vocabulary for patients with aphasia in medical settings & 699 \\
\hline
\end{tabular}

$N T W=$ Number of total words. 


\section{설문문항 개발}

설문지는 활동지원사에 대한 기본정보 9 문항, 장애인 이용자 기 본정보 9문항을 만들었다. 어휘에 대한 설문조사를 위해서는 문헌 검토 결과를 토대로 2 개 이상의 문헌에서 보고된 244 개의 어휘를 포함하되, 응답 방식은 연구 참여자의 피로도를 고려하여 체크리 스트 형태로 제공하였다. 이와 함께 문헌에서 보고하고 있지 않아 설문지 체크리스트 문항에 포함되지 않은 어휘도 개인에 따라서는 필요할 수 있으므로, 응답자가 각 지원서비스 영역별로 직접 어휘 들을 기입할 수 있도록 하였다.

개발한 설문 문항에 대해 언어병리학 박사학위를 소지하고 있으 며 $\mathrm{AAC}$ 및 관련분야에서 10년 이상 연구, 교육, 임상 경력이 있는 교수 1 명, 언어병리학 박사 과정을 수료 또는 재학 중이며 임상 경험 5 년 이상인 1 급 언어치료사 2 명, 총 3 명에게 타당도 검증을 받았다. 리커트 5 점 척도로 조사한 결과를 기반으로 5 점 만점 중 4 점 이상 인 항목만 설문지에 포함하였다.

\section{연구 대상자}

연구에는 총 105 명의 활동지원사가 온라인으로 실시된 설문조 사에 참여하였다 $(\mathrm{male}=20, \mathrm{female}=85)$. 평균연령은 51.96 세 $(\mathrm{SD}=9.09)$ 이고 평균 교육년수는 13.79 년 $(\mathrm{SD}=2.38)$ 이며 활동지원 사로 근무한 기간은 평균 56.11 개월 $(\mathrm{SD}=39.87)$ 이었다. 이들이 현 재까지 서비스를 제공한 대상자 수는 평균 3.48 명 $(\mathrm{SD}=2.84)$ 으로 그 중 의사소통에 어려움을 보인 대상자는 1.68 명 $(\mathrm{SD}=1.36)$ 이었 다(Table 2).

활동지원사에게 서비스를 제공받는 장애인 $($ male $=68$, female $=37$, mean age $=23.21[\mathrm{SD}=13.77])$ 은 지적장애 $35.5 \%$, 뇌병변장애 $21.9 \%$, 자폐성장애 $21.3 \%$, 언어장애 $14.8 \%$ 순으로 조사되었으며 이 들이 제공받는 활동지원서비스는 외출 시 동행이 전체 이용한 서비 스의 $87.6 \%$ 를 차지하는 것으로 가장 높게 나타났고, 식사도움 $61 \%$, 등하교 및 출퇴근 $61 \%$, 개인위생관리 $60 \%$, 신체기능 유지 증진 $38.1 \%$, 청소 및 주변 정돈 $34.3 \%$, 실내이동 도움 $25.7 \%$, 취사 $22.9 \%$, 그 밖의 제공서비스 $21.9 \%$, 세탁 $16.2 \%$ 순으로 나타났다(Table 3 ).

Table 2. Demographic information of the 105 personal assistants

\begin{tabular}{lrccc}
\hline Category & N & $\%$ & Mean & SD \\
\hline Sex & & & & \\
$\quad$ Male & 20 & 19.0 & & \\
Female & 85 & 81.0 & & \\
Age (year) & & & 51.96 & 9.09 \\
Education (year) & & 13.79 & 2.38 \\
Work experience (month) & & 56.11 & 39.87 \\
\hline
\end{tabular}

\section{자료분석}

IBM SPSS Statistics 26과 MS word Excel 프로그램을 이용하여 각 어휘의 활동지원사 간의 어휘공통성 점수를 원점수로 산출하 고, 활동지원사 전체 인원 수에 대한 원점수의 상대적인 비율 값을 확인하기 위해 원점수를 어휘공통성 백분율로 환산하였다. 즉, 어 휘가 필요하다고 응답한 활동지원사의 수를 전체 응답자 수로 나 눈 후 100 을 곱하여 어휘공통성 백분율을 산출하였다. 연구질문 중 지원서비스 간에 어휘공통성 백분율이 유의하게 차이가 있는지 를 살펴보기 위해 비모수 통계방법인 Kruskal-Wallis 검정을 실시 하였고, Bonferroni 사후 분석을 실시하였다.

\section{연구결과}

\section{활동지원 서비스 영역별 어휘공통성 백분율}

문헌 검토를 통해 확인된 244 개의 어휘에 대해 활동지원사들의 설문지 응답을 분석한 결과가 Table 4에 제시되어 있다. 활동지원사 간의 어휘공통성 백분율을 영역별로 살펴보면 등하교 및 출퇴근에 서 평균 $54.85 \%(\mathrm{SD}=16.72)$ 로 가장 높았으며, 그 밖의 제공서비스 평균 $53.26 \%(\mathrm{SD}=15.12)$, 식사도움 평균 $51.49 \%(\mathrm{SD}=16.75)$, 취사 영역 $47.27 \%(\mathrm{SD}=13.89)$, 청소 및 주변정돈 평균 $40.42 \%(\mathrm{SD}=12.39)$, 개인위생관리 영역은 평균 $38.04 \%(\mathrm{SD}=19.73)$, 외출 시 동행 영역

Table 3. Demographic information of people with disabilities who used the personal assistance service

\begin{tabular}{lrrrr}
\hline Category & $N$ & $\%$ & Mean & SD \\
\hline Sex & & & & \\
Male & 68 & 64.8 & & \\
Female & 37 & 35.2 & & \\
Age (year) & 105 & & 23.21 & 13.77 \\
Education & & & & \\
Uneducated & 15 & 14.3 & \\
Elementary & 33 & 31.4 & \\
Middle school & 16 & 15.2 & \\
High school & 34 & 32.4 & \\
University & 1 & 1.0 & \\
Other & 6 & 5.7 & \\
Types of disability (Duplicate selection allowed) & & \\
Intellectual disability & 55 & 35.5 & \\
Brain lesion & 34 & 21.9 & \\
Autism spectrum disorders & 33 & 21.3 & \\
Language disorder & 23 & 14.8 & \\
Other & 6 & 3.9 & \\
Hearing impairment & 2 & 1.3 & \\
Visual impairment & 1 & .6 & \\
Respiratory disorder & 1 & .6 & \\
\hline
\end{tabular}


Table 4. Descriptive statistics on the word commonality percentages in 7 personal assistance service areas

\begin{tabular}{lrrrrr}
\hline Personal assistance service area & N & $\begin{array}{c}\text { Mean } \\
(\%)\end{array}$ & $\begin{array}{r}\text { Standard } \\
\text { deviation }\end{array}$ & $\begin{array}{r}\text { Mini- } \\
\text { mum }\end{array}$ & $\begin{array}{c}\text { Maxi- } \\
\text { mum }\end{array}$ \\
\hline Personal hygiene & 27 & 38.04 & 19.73 & 3.17 & 73.02 \\
Meal supporting & 20 & 51.49 & 16.75 & 28.13 & 84.38 \\
Cleaning & 29 & 40.42 & 12.39 & 16.67 & 63.89 \\
Cooking & 26 & 47.27 & 13.89 & 29.17 & 75.00 \\
Commuting & 10 & 54.85 & 16.72 & 26.56 & 85.94 \\
Going out & 112 & 28.10 & 11.43 & 7.61 & 64.13 \\
Other services & 20 & 53.26 & 15.12 & 17.39 & 78.26 \\
\hline
\end{tabular}

은 $28.10 \%(\mathrm{SD}=11.43)$ 순으로 나타났다.

Kruskal-Wallis 검정 결과 지원서비스의 영역 간에 어휘공통성 백분율에 있어서 유의한 차이를 보이는 것으로 나타났다 $(\mathrm{H}=81.313, p<.001)$. 개인위생관리 영역과 유의한 차이를 보인 영 역은 등하교 및 출퇴근( $p=.023)$, 외출 시 동행 $(p=.018)$, 그 밖의 제 공서비스 $(p=.004)$ 였다. 식사도움 영역과 유의한 차이를 보인 영역 은 외출 시 동행 $(p<.001)$ 이었고, 청소 및 주변정돈 영역과 유의한 차이를 보인 영역은 등하교 및 출퇴근( $p=.095)$, 외출 시 동행 $(p<.001)$, 그 밖의 제공서비스 $(p=.031)$ 였다. 취사 영역과 외출 시 동행 간에도 유의한 차이가 나타났다 $(p<.001)$.

\section{어휘공통성 백분율 $50 \%$ 이상의 어휘 목록}

각 서비스 영역에 대해 총 244 개 어휘가 활동지원사 간의 어휘공 통성 백분율 순으로 Appendix 2에 제시되어 있다. 이 중 장애인 이 용자를 위한 개인 맞춤의 $\mathrm{AAC}$ 도구 제공 시, 좀 더 가중치를 두고 고려할 수 있는 어휘를 선별하기 위해 활동지원사 간 어휘공통성 백분율이 $50 \%$ 이상인 어휘를 선별한 결과 총 63 개의 어휘가 다음 과 같이 확인되었다.

개인위생관리 영역에서는 총 27 개의 어휘 중 10 개가 $50 \%$ 이상의 백분율을 보이는 것으로 나타났다. 해당 어휘를 백분율 순으로 살펴 보면, '물'(73.02\%), '화장실'(71.43\%), '팬티'(60.32\%), '비누'(60.32\%), '양말'(55.56\%), ‘옷'(55.56\%), '가방'(55.56\%), '신/신발'(53.97\%), '운 동화'(53.97\%), '바지'(50.79\%) 순으로 나타났다.

식사도움 영역에서는 총 20 개의 어휘 중 10 개가 해당하였으며 이 를 백분율 순으로 살펴보면, '물/생수'(84.38\%), ‘밥'(73.44\%), '간식' (70.31\%), '고기'(70.31\%), '김치'(65.63\%), '국'(64.06\%), '과자' (60.94\%), '빵'(60.94\%), ‘우유'(57.81\%), '바나나'(50.00\%) 순으로 나 타났다.

청소 및 주변정돈 영역에서는 총 29 개의 어휘 중 9 개가 해당하였 고 ‘TV/텔레비전'(63.89\%), ‘칫솔’(58.33\%), ‘화장지'(58.33\%), '휴지’
(55.56\%), '휴지통’(55.56\%), ‘치약'(52.78\%), ‘침대’(50.00\%), '냉장고' (50.00\%), '수건'(50.00\%) 순으로 나타났다.

취사 영역에서는 총 26 개의 어휘중 10 개가 해당하였고 '국'(75.00\%), '고기'(70.83\%), '김치'(70.83\%), '물'(70.83\%), '계란/달걀'(62.5\%), ‘라 면'(62.5\%), '김'(54.17\%), ‘떡'(54.17\%), '설탕'(50.00\%), '고구마'(50.00\%) 순으로 나타났다.

등하교 및 출퇴근 영역에서는 총 10 개의 어휘 중 7 개의 어휘 즉, '가 방'(85.94\%), '학교'(76.56\%), '준비물'(59.38\%), '공책/노트'(54.69\%), '연필' (54.69\%), '숙제'(51.56\%), '책'(50.00\%)이 포함되었다.

외출 시 동행 영역에서는 총 112 개의 어휘 중 5 개의 어휘만 $50 \%$ 이상의 어휘공통성 백분율을 보이는 것으로 나타났다. 이들 어휘로 는 ‘화장실'(64.13\%), '자동차'(55.43\%), '물'(54.35\%), '병원'(51.09\%), '학교'(50.00\%)가 포함되었다.

그 밖의 제공서비스 영역에서는 총 20 개 중에서 12 개 어휘가 해당 되어, 'TV/텔레비전'(78.26\%), '과자/까까'(73.91\%), '운동'(69.57\%), '자동차'(69.57\%), '집'(69.57\%), '친구'(60.87\%), '게임'(60.87\%), '컴퓨터' (56.52\%), '위치/방향'(56.52\%), '공놀이'(52.17\%), '장난감'(52.17\%), '전화'(52.17\%) 순으로 나타났다.

\section{활동지원사의 추가 보고 어휘}

활동지원사들이 장애인 이용자와의 의사소통에 필요하다고 추 가적으로 답한 어휘는 총 224 개로 각 서비스 영역별로 살펴보면 다 음과 같다.

개인위생관리 영역에서는 '감사, '도움, '린스, '마스크', '머리끈, '목발, '물티슈, '바닥', ‘버튼, '비닐봉지', '생리대', '선생님, '소독약', '손 소독제', '손수건', '아픔, '접시', '찍찍이(벨크로)' '휠체어’의 어 휘가 추가 응답으로 확인되었다 $(\mathrm{N}=19)$.

식사도움 영역에서는 '갈치조림', '고구마', '고추장', '공기', '국그 릇, '김치전, '깻잎, ‘나물, ‘맛', ‘매움, ‘맥주’, ‘받침’, ‘밥그릇, ‘밥상', ‘배고픔, ‘배부름, ‘소주, ‘수건', ‘쌈장', ‘양배추, ‘어묵, ‘얼음물', ‘장 떡', '전자레인지', '집게', '치킨', '컵, '턱받이', ‘호박잎' '홍시', '휴지' 가추가 어휘로 언급되었다 $(\mathrm{N}=31)$.

청소 및 주변정돈 영역에서는 '높이', '때', '락스, '선반', '세정제', '수압,' '스위치', '온도, '잠옷, '청결, '칫솔걸이', '카펫', '화분'의 어휘 가 보고되었다 $(\mathrm{N}=13)$.

취사 영역에서는 '가스, '가스레인지', '기장떡', '김치찌개', '된장 찌개', ‘무화과', ‘밥솥/압력밥솥, ‘밥통', '분리수거', ‘수제비', '요리 사, '위험, '일회용 그릇', '종이컵, '참외', '칼국수', ‘화재'가 추가되 었다 $(\mathrm{N}=17)$.

등하교 및 출퇴근 영역에서는 '감각통합', '공, '교과목명', '교무 


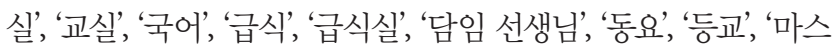
크, '명찰', '목발', '문, '미술, '보조 가방', ‘복습, '복지관', '선생님', '소독액, ‘수업, '수업시간', ‘수영', ‘수학, '쉬는 시간', '시간', '식사', '신호', '신호등, '실내화, '아침' '안전벨트, ‘언니', ‘언어', ‘엄마', ‘에어 컨', '예습, '옷, '인사', '자동차', '장애인 콜택시', '점심시간', '지각', '지갑,' ‘지지대', '지킴이', ‘지하철', '질서', ‘차', '치료실', '친구', '카드', '핀', ‘화장실', ‘화장품' '횡단보도', ‘휠체어'가 추가 응답되었다 $(\mathrm{N}=58)$.

외출 시 동행 영역에서 추가 언급된 어휘로는 '간식', '강아지', '기 타(악기)', ‘꽃구경', ‘놀이동산', ‘드럼', '목줄, '배변 봉투, '백화점', ‘버거', '산책', '순대국, '술집, '신호등', ‘악기', '인도', ‘장례식장', ‘조 심,' '지하상가', '치료실'이 있다 $(\mathrm{N}=20)$.

그 밖의 제공서비스 영역에서는 '가로등', '강아지', ‘단어', '데이 트', ‘도시락', '말벗', '물통', '분리수거', '산책', ‘소리', '안전벨트', '양 보', '여자친구, '연습, '우산, '킥보드, '할머니', '할아버지', '핸드폰', ‘형', '화장실', '화재', '활동'이 추가 어휘로 포함되었다 $(\mathrm{N}=23)$.

문헌에서 어휘를 보고하지 않아 체크리스트 설문 문항에서 제외 된 3개 서비스 영역에 대해서도 추가 어휘를 수집한 결과, 우선 신 체기능 유지 증진 영역에서는 '거리', '경직', '고마움, '단위', '달리 기', ‘매트, ‘모서리', ‘무게’, ‘무게중심, ‘바퀴', ‘발 받침', ‘발판', ‘속도', '수치', '운동화, '자전거', '점프', '정지', ‘지팡이', ‘진행', ‘회전'이 추가 되었다(N=21). 실내이동 도움 영역에서는 ‘방석', '방지', ‘수건' ‘욕 창', '조심'의 어휘가 확인되었고 $(\mathrm{N}=5)$, 세탁 영역에서는 '건조기', '건조대', '드라이클리닝', '베란다, '빨래망', '빨래판', '섬유유연제', '세제', '양말', ‘옷장', ‘이불 빨래, '정돈, '정리/정돈, '집게/빨래집게', '팬티', '햇빛' '헹굼'이 추가 응답으로 확보되었다( $\mathrm{N}=17)$.

\section{논의 및 결론}

본 연구는 장애인과 활동지원사 간의 원활한 의사소통을 도모 하기 위해 문헌에서 공통적으로 보고한 명사 어휘를 활동지원 서 비스의 영역별로 분류한 후, 활동지원사에게 체크리스트 형태로 설문조사를 실시하여 어휘공통성 백분율이 높은 주요 명사 어휘 를 살펴보고, 주관적 어휘 보고를 통해 부수어휘 목록을 보완하고 자하였다.

우선 활동지원사 간의 평균 어휘공통성 백분율을 분석한 결과, 지원서비스 영역 별로 차이가 있는 것으로 나타났다. 가장 극명한 평균 값의 차이를 보인 두 서비스 영역을 비교하자면, 등하교 및 출 퇴근과 관련한 어휘에 대해서는 평균 백분율이 $54.85 \%$ 로 나타나 전체 활동지원사의 반 이상이 제시된 어휘에 대해 필요하다고 응답
한 반면, 외출 시 동행 영역에서는 평균 백분율이 $28.10 \%$ 로 나타나 어휘에 대한 공통된 의견이 덜 집약되는 것으로 나타났다. 이러한 특징은 외출 상황에서 필요로 하는 어휘가 장애인 이용자의 외출 목적과 도착 장소 및 그곳에 도달하기까지의 경로에 따라 달라질 수 있기 때문으로 보인다. 또한 문헌에서 보고하는 등하교 및 출퇴 근에 해당하는 어휘는 중복 어휘를 제외하고 10 개였던 반면, 외출 시 동행에 해당하는 어휘는 서로 다른 112 개의 어휘가 확보되었다 는 점도 사용자가 느끼는 어휘 필요성이 다양할 수 있음을 반증해 준다 하겠다. 부수어휘가 각각의 대화 상황별 특성을 핵심어휘보 다는 잘 반영해주기는 하나(Beukelman et al., 1989; Stuart et al., 1997), 문헌과 설문조사에 기반한 집단의 의견이 반영된 만큼, 부수 어휘라 하더라도 개인이 필요로 하는 어휘가 상황마다 다를 수 있 다는 점을 주지해야 하겠다. 따라서 임상 현장에서 본 연구 결과를 활용할 때에는 영역별로 제시된 부수어휘 목록은 참고하되, 해당 영역의 평균 어휘공통성 백분율이 다른 영역보다 상대적으로 낮은 경우에는 개별 장애인 이용자가 필요로 하는 어휘를 추가 및 보완 하는작업이 요구된다.

활동지원사간의 어휘공통성 백분율이 $50 \%$ 이상인 어휘를 살펴 본 결과 전체 244 개의 어휘 중 63 개가 해당하여 전체의 $25.82 \%$ 를 차지하는 것으로 나타났다. 핵심어휘가 화자 또는 대화 상대자와 상관없이 어휘 공통성이 높은 반면 부수어휘는 공통적으로 필요 로 하는 어휘가 개인 간 차이가 있다는 점이 선행연구와 마찬가지 로 본 연구에서도 확인되었다(Balandin \& Iacono, 1998; Marvin et al., 1994; Shin \& Hilll, 2016; Shin et al., 2021; Trembath et al., 2007). 특히, 부수어휘의 수를 가장 많이 보유한 외출 시 동행에서 는 $50 \%$ 이상의 어휘공통성 백분율을 보인 어휘가 5 개에 그쳐, 지원 서비스 영역 중 가장 적은 어휘 수를 보였다. 이러한 결과는 앞서 살 펴본 영역별 평균 어휘공통성 백분율이 낮은 결과와도 관련된 것 으로 다른 지원서비스 영역보다 외출 시 동행 서비스를 지원할 때 개별 장애인의 요구가 다양하다는 것을 보여준다. 외출 시 동행 서 비스는 활동지원서비스 중에서도 가장 많이 제공되는 영역으로 (Kim, 2014), 본 연구의 고려 대상자의 대다수가 이동 지원을 필요 로 하는 지적장애, 자폐범주성장애, 뇌병변장애라는 점(Ministry of Health and Welfare, 2019)을 고려하였을 때, 개개인의 요구가 다 양해짐에 따라 어휘공통성은 낮아지게 된 이유를 유추해 볼 수 있 겠다.

현장에서는 활동지원사가 장애인과 $\mathrm{AAC}$ 도구를 사용하여 의 사소통하고자 할 때 $50 \%$ 이상의 어휘공통성 백분율을 보인 어휘 를 우선적으로 고려하여 도구에 포함할지 여부를 결정하고, $50 \%$ 미만의 어휘목록과 주관적 보고를 통해 얻어진 어휘목록을 그 다 
음의 참고 자료로 활용할 수 있을 것이다. 아울러 본 연구에서 문헌 과 설문조사를 통해 얻어진 부수어휘 목록 외에도 개인이 필요한 어휘가 있을 수 있다는 점을 활동보조사는 주지할 필요가 있다. 개 별 장애인이 필요로 하는 상황별 부수어휘를 확보하기 위해 구어 사용에 어려움이 있는 이들이 보내는 비구어적인 요구 신호를 잘 관찰하고 이를 $\mathrm{AAC}$ 도구를 사용하여 효과적으로 표현할 수 있도 록 해야 하며(Siegel \& Wetherby, 2000), 장애인 가족과 지속적으로 소통하면서 이용자가 필요로 하는 어휘를 추가하는 과정이 이루어 져야할 것이다.

마지막으로 활동지원사들은 224 개의 다양한 어휘를 추가로 보 고하였다. 영역 간의 인접성이 높은 경우, 가령 취사와 식사 도움의 어휘를 살펴보면 음식과 관련한 개인적인 어휘가 다수 제안되는 특 징을 보이기도 했으나(예: 치킨, 호박잎, 수제비, 칼국수), 서비스를 제공받는 장애인의 입장에서 필요로 하는 어휘가 다수 추가된 것 도 확인할 수 있었다. 예를 들어 개인위생관리 영역에서는 비장애 인일 경우 언급되지 않았을 수 있는 ‘휠체어', ‘목발’이 화장실 이용 에 있어서 자세를 유지하거나 이동하는 데 있어서 필요하다고 보고 되었고, 청소 및 주변정돈 영역에서는 '선반', '스위치', '칫솔걸이', '카펫', '화분' 등 장애인이 섬세하게 청소하기에는 어려움이 있는 사물 어휘가 포함된 것을 알 수 있다. 등하교 및 출퇴근 영역에서는 '안전벨트', '장애인 콜택시', '지지대' 등이 추가되었고 외출 시 동행 에서는 '배변 봉투'가 추가 언급되는 등 문헌에서 놓치고 있는 장애 인을 위한주요 어휘가 주관적 보고로 보완된 것을 알 수 있다.

10 개의 서비스 영역 중에서 2 개 이상의 문헌에서 보고하지 않아 설문 문항에서는 제외되었던 3 개의 서비스 영역에 대해 주관적으 로 보고한 어휘를 살펴보면, 신체 기능 유지 증진 영역에서는 '매 트, '모서리', '무게중심', ‘바퀴', '발 받침' '발판' ‘회전', 실내이동 도 움 영역에서는 '욕창' 과 같이 체위 변경과 관련된 다양하고 세부적 인 어휘들이 다수 포함된 것으로 나타났다. 세탁 영역은 비장애인 과 마찬가지로 일상생활을 청결하게 유지하기 위해 필요한 주요 활 동인 만큼 '건조기', '건조대', ‘드라이클리닝', ‘베란다, '빨래망', ‘빨 래판', '섬유유연제, '세제', '양말', '옷장', '이불 빨래' '정돈' '정리/정 돈, ‘집게/빨래집게’, ‘팬티', ‘햇빛, ‘헹굼’ 등 관련된 다양한 어휘들 이 부수어휘로 언급되었다. 이들 어휘들은 개별 장애인의 필요에 따라 의사소통 상황별로 $\mathrm{AAC}$ 의사소통 판을 구성할 때 탑재할 수 있을 것이다. 다만, 부수어휘의 특성상 장소, 개인, 활동, 상황 등에 따라 영향을 받기 때문에(Balandin \& Iacono, 1998; Mcginnis \& Beukelman, 1989) 어휘의 활용성과 대상자의 선호도와 필요 (Musselwhite \& St. Louis, 1988)를 고려하여 알맞은 어휘를 선정해 야할 것이다.
장애인이 일상생활에 필요한 활동을 수행하기 위해 활동지원사 의 도움이 필요한 만큼, 이들과의 원활한 의사소통은 필수적이다 (Song \& Jeong, 2009). 본 연구는 구어 의사소통에 어려움이 있는 장애인 당사자를 대상으로 직접 어휘를 수집하지 못했다는 한계점 이 있으나, 문헌의 어휘자료와 이들을 일상 속에서 밀착 지원하는 활동지원사의 설문조사를 통해 각 상황별로 필요한 부수어휘를 수집하여 현장에서 활용할 수 있는 근거 자료를 제공하였다는 점 에서 의의를 갖는다. 각각의 지원서비스 영역별 부수어휘는 활동지 원서비스를 이용할 때에만 국한되어 사용되는 것이 아니라, 장애인 이 가정 및 지역사회에서 다양한 사람들과 관계를 맺으며 의사소 통 할 때에도 고려될 수 있는 어휘들이다. 따라서 본 연구의 어휘 목 록은 장애인 가족, 활동지원사, 언어재활사, 특수교사, 사회복지사 등 다양한 관계자들이 장애인의 의사소통 단절(Fried-Oken \& Granlund, 2012; Im, 2018; Jeon \& Hwang, 2017; Jeong, 2018; Kim, 2012)을 함께 극복하기 위해 활용할 수 있을 것으로 기대한다.

본 연구에서는 명사만을 어휘 분석에 포함하였기 때문에 부수어 휘를 총괄적으로 파악하는 데에는 제한이 있다. 추후 연구에서는 보다 다양한 품사로 확장하여 상황별로 필요한 부수어휘를 분석 하는 작업이 이뤄져야 하겠다. 아울러 장애인의 연령과 장애 유형 에 따라 생태학적 생활 범위와 대화 상황마다 요구하는 어휘가 달 라질 수 있으므로 이에 대한 보완 연구가 필요하다. 마지막으로 선 행연구에서 보고하는 핵심어휘 목록과 본 연구에서 확보한 부수어 휘를 통합하여 장애인이 일상에서 효과적으로 활용할 수 있는 $\mathrm{AAC}$ 중재접근안을 고안하고 그 효과성을 검증하는 연구가 수행 되어야 할 것이다.

\section{REFERENCES}

( ${ }^{*}$ indicates studies used for literature review)

American Speech-Language-Hearing Association. (2005). Roles and responsibilities of speech-language pathologists with respect to augmentative and alternative communication: Position Statement. Retrieved from www.asha. org/policy.

Banajee, M., Dicarlo, C., \& Stricklin, S. (2003). Core vocabulary determination for toddlers. Augmentative and Alternative Communication, 19(2), 6773.

Balandin, S., \& Iacono, T. (1998). A few well-chosen words. Augmentative and Alternative Communication, 14(3), 147-161.

Balandin, S., \& Iacono, T. (1999). Crews, wusses, and whoppas: core and fringe vocabularies of Australian meal-break conversations in the workplace. 
Augmentative and Alternative Communication, 15(2), 95-109.

Beukelman, D. R., Jones, R., \& Rowan, M. (1989). Frequency of word usage by nondisabled peers in integrated preschool classrooms. Augmentative and Alternative Communication, 5(4), 243-248.

Beukelman, D. R., \& Miranda, P. (2013). Augmentative and alternative communication: supporting children and adult with complex communication need (4th ed.). Baltimore, MD: Paul H. Brookes.

Boenisch, J., \& Soto, G. (2015). The oral core vocabulary of typically developing English-speaking school-aged children: implications for AAC practice. Augmentative and Alternative Communication, 31(1), 77-84.

${ }^{\star}$ Chang, H. J., Jeon, H. S., \& Kim, H. J. (2014). Study on selection of basic vocabulary for elementary school students: focused on basic vocabulary in the lower grades. Korean Speech-Language \& Hearing Association, 23(1), 157-170.

Clendon, S. A., \& Erickson, K. A. (2008). The vocabulary of beginning writers: Implications for children with complex communication needs. Augmentative and Alternative Communication, 24(4), 281-293.

Choi, B. C., \& Kim, Y. R. (2016). Qualitative inquiry on problems and improvements perceived by parents of children with disabilities who use personal assistance service. Korean Journal of Physical, Multiple \& Health Disabilities, 59(3), 207-266.

Croft, W. (2000). Parts of speech as language universals and as language-particular categories, In P. M. Vogel \& B. Comrie (Eds.), Approaches to the typology of word Classes (pp 65-102), Berlin: Mouton de Gruyter.

Deckers, S. R. J. M., Van Zaalen, Y., Van Balkom, H., \& Verhoeven, L. (2017). Core vocabulary of young children with Down syndrome. Augmentative and Alternative Communication, 33(2), 77-86.

Fried-Oken, M., \& Granlund, M. (2012). AAC and ICF: a good fit to emphasize outcome. Augmentative and Alternative Communication, 3(2), 77-89.

Hill, K. J. (2001). The development of a model for automated performance measurement and the establishment of performance indices for augmented communicators under two sampling conditions (Doctoral dissertation). University of Pittsburgh, Pittsburgh, USA.

Hwang, J. H. (2014). Policy implication of the daily lives of people with severe disabilities. Health and Welfare Policy Forum, 217, 18-28.

Im, M. S. (2018). An analysis on the needs of adults with brain lesion for AAC intervention services (Master's thesis), Gachon University, Seongnam, Korea.

*Ji, H. (2018). Severity-dependent situational vocabulary: reported by caregivers of inpatients with aphasia (Master's thesis), Yonsei University, Seoul, Korea.
Jeon, J. A., \& Hwang, S. J. (2017). The educational needs and communication difficulties of school-aged children with autism spectrum disorder as perceived by personal assistants for the disabled. Journal of the Korean Association for Persons with Autism, 17(3), 91-114.

Jeong, S. H. (2018). Communication difficulties of communication disorder and speech therapy by personal assistants for the disabled (Master's thesis). Daegu University, Gyeongbuk, Korea.

Kim, B. S. (2012). A study on the close care relation process from the perspective of persons with disability. Journal of Disability and Welfare, 18, 1942.

${ }^{\star}$ Kim, J. A., \& Yeon, S. J. (2019). A case study on the AAC intervention using community adapted activities for people with physical disabilities. The Korean Society for Augmentative and Alternative Communication, 7(1), 153171.

Kim, J. I., \& Han, K. I. (2016). Core vocabulary of preschool children with or without disabilities for augmentative and alternative communication intervention. The Journal of Special Children Education, 18(2), 185-213.

Kim, S. H. (2014). Policy issues of personal assistance service (PAS) for the disabled. Health and Welfare Policy Forum, 217, 18-28.

${ }^{\star}$ Kim, S. Y., Kim, H., \& Kim, J. I. (2019). A study on the language and prototype device for the communication of people with deaf-blindness. The Korean Journal of Visual Impairment, 35(1), 19-39.

Kim, Y. T., Park, H. J., \& Min, H. K. (2003). School-aged children and adult's core vocabulary for the development of an augmentative and alternative communication tool. Korean Journal of Communication Disorders, 8(2), 93-110.

Laubscher, E., \& Light, J. (2020). Core vocabulary lists for young children and considerations for early language development: a narrative review. Augmentative and Alternative Communication, 36(1), 43-53.

Liu, C., \& Sloane, Z. (2006). Developing a core vocabulary for a mandarin Chinese AAC system using word frequency data. International Journal of Computer Processing of Languages, 19(4), 285-300.

Marvin, C., Beukelman, D. R., \& Bilyeu, D. (1994). Vocabulary-use patterns in preschool children: effects of context and time sampling. Augmentative and Alternative Communication, 10(4), 224-236.

McGinnis, J. S., \& Beukelman, D. (1989). Vocabulary requirements for writing activities for the academically mainstreamed students with disabilities. Augmentative and Alternative Communication, 5(3), 183-191.

Ministry of Health and Welfare. (2019). Training curriculum for personal assistant with the disabled. Sejong: Author. 
${ }^{*}$ Moon, K. H. (2011). A study of Korean vocabulary education using lexical field. The Association of Field Studies in Korean Language Education, 5(2), 7-47.

*Moon, J. Y., \& Hwang, B. M. (2015). Development of 'self-confidence' AAC board for the olds with communication disorders. AAC Research \& Practice, 3(2), 139-152.

Musselwhite, C., \& St. Louis, K. (1988). Communication programming for persons with severe handicaps (2nd ed.). Austin, TX:PRO-Ed.

${ }^{\star}$ Lee, J. A., Pyun, D. W., \& Kwak, S. C. (2011). Study of the selection of basic learning vocabulary for children with developmental disabilities: focus on children with kindergarden and elementary school. Korean Journal of Special Education, 46(2), 29-50.

${ }^{*}$ Lee, J. E., \& Park, E. H. (2000). Development of AAC core vocabulary list: vocabulary selection strategies based on communication contexts. Rehabilitation International Korea, 4(1), 96-122.

Lee, Y. M., Kim, Y. T., \& Park, E. H., (2005). A preliminary study for the core and fringe AAC vocabulary used by elementary school students. Korean Journal of Communication Disorders, 10(1), 134-152.

Oh, K. A., Nam, K. W., \& Kim, S. J. (2014). The development of verb through semantic categories in the spontaneous speech of preschoolers. Journal of Speech-Language \& Hearing Disorders, 23(4), 63-72.

${ }^{*}$ Pae, S. Y., \& Kwak, K. J. (2011). Korean version M-B CDI (K M-B CDI). Seoul: Mindpress Aptitude Publishing Co. Ltd.

${ }^{\star}$ Park, E. H. (1996). Core vocabulary for nonverbal elementary school students with cerebral palsy. The Korean Sociey of Special Education, 13(1), 91-115.

Park, H. Y., \& Kim, Y. T. (2015). Analyses of core and fringe vocabulary of adults with intellectual disabilities living in community group homes. Special Education Research, 14(2), 81-103.

${ }^{\star}$ Park, S. H. (1999). Development of an inventory of functional vocabulary for community functioning of students with mental retardation. Rehabilitation International Korea, 3(1), 23-57.

Robillard, M., Mayer-Crittenden, C., Minor-Corriveau, M., \& Belanger, R. (2014). Monolingual and bilingual children with and without primary language impairment: core vocabulary comparison. Augmentative and Alternative Communication, 30(3), 267-278.

Shin, S. E. (2017). Analysis on base forms of high frequency predicates to develop augmentative and alternative communication system. Communication Sciences \& Disorders, 22(1), 159-169.
Shin, S., \& Hill, K. (2016). Korean word frequency and commonality study for augmentative and alternative communication. International Journal of Language \& Communication Disorders, 51(4), 415-429.

Shin, S., \& Park, D. (2020). A literature review of AAC core vocabulary lists of children and adults. Journal of Speech-Language \& Hearing Disorders, 29(1), 71-83.

Shin S., Park, H., \& Hill, K. (2021). Identifying the core vocabulary for adults with complex communication needs from the British National Corpus by analyzing grouped frequency distributions. Journal of Speech, Language, and Hearing Research, 64(11), 4329-4343.

Siegel, E., \& Wetherby, A. (2000). Nonsymbolic communication. In. M.E. Snell \& F. Brown (Eds.), Instruction of students with severe disabilities (5th ed.) (pp. 409-451). Upper Saddle River, NJ: Merrill/Prentice-Hall.

Snodgrass, M. R., Stoner, J. B., \& Angell, M. E. (2013). Teaching conceptually referenced core vocabulary for initial augmentative and alternative communication. Augmentative and Alternative Communication, 29(4), 322333.

Song, H. J., Song, Y. M., \& Park, H. J. (2015). Characteristics of vocabulary use in narrative tasks in preschool children: A preliminary study for AAC application. Communication Sciences \& Disorders, 20(3), 386-399.

Song, J. S., \& Jeong, J. H. (2009). A study on the comparative service satisfaction of disabled person using personal assistance service. Journal of Rehabilitation Research, 13(1), 187-213.

Stuart, S., Beukelman, D. R., \& King, J. (1997). Vocabulary use during extended conversations by two cohorts of older adults. Augmentative and Alternative Communication, 13(1), 40-47.

Stuart, S., Lasker, J. P., \& Beukelman, D. R. (2000). AAC message management. In D. R. Beukelman, K. M. Yorkston., \& J. Reichle (Eds.), Augmentative and alternative communication for adult with acquired neurologic disorders (pp.25-54). Baltimore: Paul H. Brookes Publishing Co.

Trembath, D., Balandin, S., \& Togher, L. (2007). Vocabulary selection for Australian children who use augmentative and alternative communication. Journal of Intellectual \& Developmental, 32(4), 291-301.

Wood, C., Appleget, A., \& Hart, S. (2016). Core vocabulary in written personal narratives of school-age children. Augmentative and Alternative Communication, 32(3), 198-207.

Yorkston, K., Honsinger, M., Dowden, P., \& Marriner, N. (1989). Vocabulary selection: a case report. Augmentative and Alternative Communication, 5(2), 101-108. 
Appendix 1. Personal assistance service areas (Retrieved from Ministry of Health and Welfare, 2019)

\begin{tabular}{|c|c|}
\hline 구분 & 세부내용 \\
\hline \multicolumn{2}{|l|}{ 신체활동지원 } \\
\hline 개인위생관리 & $\begin{array}{c}\text { 목욕도움(목욕준비, 몸씻기 보조 등), 구강관리(양치질 도움, 틀니 손질 등), 세면 도움(세면준비, 세면 보조 등), 배설도움(배뇨도움, } \\
\text { 화장실 이동 보조 등), 옷 갈아입히기(의복준비, 속옷 갈아입히기 등) }\end{array}$ \\
\hline 신체기능 유지 증진 & 체위 변경(체위 변경 도움, 일어나 앉기 도움 등), 신체기능의 증진(관절구축 예방활동, 기구사용운동 보조 등) \\
\hline 식사 도움 & 식사 차리기, 식사 보조, 구토물 정리 등 \\
\hline 실내이동 도움 & 실내에서 휠체어로 옮겨 타기, 집안 내 걷기 도움 등 \\
\hline \multicolumn{2}{|l|}{ 가사활동지원 } \\
\hline 청소 및 주변 정돈 & 수급자가 거주하는 장소(방, 거실) 및 화장실 청소, 쓰레기 분리수거, 내부 정리, 이부자리 정돈, 화장대·책장 정리, 옷장-서랍장 정리 등 \\
\hline 세탁 & 수급자의 옷, 양말, 수건, 침구류, 걸레 등의 세탁 및 삶기 등 \\
\hline 취사 & 식재료 준비, 밥 짓기, 국·반찬 하기, 식탁 청소, 설거지, 행주 삶기, 음식물 쓰레기 분리수거 등 \\
\hline \multicolumn{2}{|l|}{ 사회활동지원 } \\
\hline 등하교 및 출퇴근 지원 & 출퇴근 및 등하교 보조(부축, 동행 포함), 직장이나 학교 등에서 식사 및 화장실 이용 보조 등 신체활동지원 \\
\hline 외출 시 동행 & 산책, 물품구매, 종교활동, 복지시설 이용, 은행, 관공서, 병원 등 방문 및 귀가 시 부축 또는 동행, 외출 시의 신체활동지원 \\
\hline 그 밖의 제공 서비스 & $\begin{array}{l}\text { 수급자 자녀의 양육 보조(만 6세 이하 등 예외적인 경우에 한함), 생활상의 문제 상담 및 의사소통 도움 등 위에 열거되지 않은 } \\
\text { 서비스 내용 기록 }\end{array}$ \\
\hline
\end{tabular}


Appendix 2. Nouns with high word commonalities across the 105 personal assistants

(1) 개인위생관리 $(N=27)$

\begin{tabular}{|c|c|c|c|c|c|c|c|c|}
\hline$\#$ & 어휘 & 어휘공통성 백분율(\%) & $\#$ & 어휘 & 어휘공통성 백분율(\%) & $\#$ & 어휘 & 어휘공통성 백분율(\%) \\
\hline 1 & 물 & 73.02 & 11 & 신체부위 & 49.21 & 21 & 치마 & 15.87 \\
\hline 2 & 화장실 & 71.43 & 12 & 모자 & 41.27 & 22 & 목도리 & 15.87 \\
\hline 3 & 팬티 & 60.32 & 13 & 안경 & 38.1 & 23 & 카디건 & 15.87 \\
\hline 4 & 비누 & 60.32 & 14 & 잠바 & 36.51 & 24 & 코트/외투 & 15.87 \\
\hline 5 & 양말 & 55.56 & 15 & 단추 & 36.51 & 25 & 허리띠 & 14.29 \\
\hline 6 & 옷 & 55.56 & 16 & 주머니 & 33.33 & 26 & 핸드백 & 9.52 \\
\hline 7 & 가방 & 55.56 & 17 & 잠옷 & 31.75 & 27 & 넥타이 & 3.17 \\
\hline 8 & 신/신발 & 53.97 & 18 & 장갑 & 30.16 & & & \\
\hline 9 & 운동화 & 53.97 & 19 & 남/남자 & 26.98 & & & \\
\hline 10 & 바지 & 50.79 & 20 & 구두 & 22.22 & & & \\
\hline
\end{tabular}

(2) 식사도움 $(N=20)$

\begin{tabular}{lcccccccr}
\hline$\#$ & 어휘 & 어휘공통성 백분율(\%) & $\#$ & 어휘 & 어휘공통성 백분율(\%) & $\#$ & 어휘 & 어휘공통성 백분율(\%) \\
\hline 1 & 물/생수 & 84.38 & 8 & 빵 & 60.94 & 15 & 접시 & 39.06 \\
2 & 밥 & 73.44 & 9 & 우유 & 57.81 & 16 & 포크 & 37.50 \\
3 & 간식 & 70.31 & 10 & 바나나 & 50.00 & 17 & 된장찌개 & 31.25 \\
4 & 고기 & 70.31 & 11 & 주스 & 45.31 & 18 & 떡 & 31.25 \\
5 & 김치 & 65.63 & 12 & 음식 & 43.75 & 19 & 찌개 & 28.13 \\
6 & 국 & 64.06 & 13 & 김치찌개 & 43.75 & 20 & 콜라 & 28.13 \\
7 & 과자 & 60.94 & 14 & 라면 & 43.75 & & & \\
\hline
\end{tabular}

(3) 청소 및 주변 정돈 $(\mathrm{N}=29)$

\begin{tabular}{lcccccccc}
\hline$\#$ & 어휘 & 어휘공통성 백분율(\%) & $\#$ & 어휘 & 어휘공통성 백분율(\%) & $\#$ & 어휘 & 어휘공통성 백분율(\%) \\
\hline 1 & TV/텔레비전 & 63.89 & 11 & 이불 & 44.44 & 21 & 커튼 & 33.33 \\
2 & 칫솔 & 58.33 & 12 & 계단 & 44.44 & 22 & 옷장 & 30.56 \\
3 & 화장지 & 58.33 & 13 & 걸레 & 41.67 & 23 & 빗자루 & 27.78 \\
4 & 휴지 & 55.56 & 14 & 목욕탕 & 41.67 & 24 & 라디오 & 25.00 \\
5 & 휴지통 & 55.56 & 15 & 비누 & 41.67 & 25 & 빗 & 25.00 \\
6 & 치약 & 52.78 & 16 & 컵 & 41.67 & 26 & 소파 & 25.00 \\
7 & 침대 & 50.00 & 17 & 부억/주방 & 38.89 & 27 & 열쇠 & 25.00 \\
8 & 냉장고 & 50.00 & 18 & 쓰레기 & 38.89 & 28 & 카메라 & 25.00 \\
9 & 수건 & 50.00 & 19 & 베개 & 33.33 & 29 & 피아노 & 16.67 \\
10 & 방 & 44.44 & 20 & 옷걸이 & 33.33 & & & \\
\hline
\end{tabular}

(4) 취사 $(\mathrm{N}=26)$

\begin{tabular}{lcccccccc}
\hline$\#$ & 어휘 & 어휘공통성 백분율(\%) & $\#$ & 어휘 & 어휘공통성 백분율(\%) & $\#$ & 어휘 & 어휘공통성 백분율(\%) \\
\hline 1 & 국 & 75.00 & 11 & 감자 & 45.83 & 21 & 치즈 & 33.33 \\
2 & 고기 & 70.83 & 12 & 쌀 & 45.83 & 22 & 콩 & 33.33 \\
3 & 김치 & 70.83 & 13 & 생선 & 45.83 & 23 & 밤 & 33.33 \\
4 & 물 & 70.83 & 14 & 음식 & 45.83 & 24 & 옥수수 & 33.33 \\
5 & 계란/달걀 & 62.50 & 15 & 토마토 & 41.67 & 25 & 호박 & 앙근 \\
6 & 라면 & 62.50 & 16 & 무 & 33.33 & 29.17 \\
7 & 김 & 54.17 & 17 & 배추 & 37.50 & 26 & & \\
8 & 떡 & 54.17 & 18 & 소금 & 37.50 & & & \\
9 & 설탕 & 50.00 & 19 & 닭고기 & 37.50 & & & \\
10 & 고구마 & 50.00 & 20 & 얼음 & 37.50 & & & \\
\hline
\end{tabular}

(5) 등하교 및 출퇴근 $(N=10)$

\begin{tabular}{lcccccccc}
\hline$\#$ & 어휘 & 어휘공통성 백분율(\%) & $\#$ & 어휘 & 어휘공통성 백분율(\%) & $\#$ & 어휘 & 어휘공통성 백분율(\%) \\
\hline 1 & 가방 & 85.94 & 5 & 연필 & 54.69 & 9 & 지우개 & 42.19 \\
2 & 학교 & 76.56 & 6 & 숙제 & 51.56 & 10 & 휴게실 & 26.56 \\
3 & 준비물 & 59.38 & 7 & 책 & 50.00 & & \\
4 & 공책/노트 & 54.69 & 8 & 학생 & 46.88 & & \\
\hline
\end{tabular}

(Continued to the next page) 
Appendix 2. Continued

(6) 외출 시 동행 $(\mathrm{N}=112)$

\begin{tabular}{|c|c|c|c|c|c|c|c|c|}
\hline$\#$ & 어휘 & 어휘공통성 백분율(\%) & $\#$ & 어휘 & 어휘공통성 백분율(\%) & $\#$ & 어휘 & 어휘공통성 백분율(\%) \\
\hline 1 & 화장실 & 64.13 & 39 & 내과 & 31.52 & 77 & 드라이 & 20.65 \\
\hline 2 & 자동차 & 55.43 & 40 & 메뉴 & 31.52 & 78 & 의료 & 20.65 \\
\hline 3 & 물 & 54.35 & 41 & 통장 & 31.52 & 79 & 잔돈 & 20.65 \\
\hline 4 & 병원 & 51.09 & 42 & 위치/방향 & 30.43 & 80 & 환불 & 20.65 \\
\hline 5 & 학교 & 50.00 & 43 & 경찰서 & 30.43 & 81 & 회사 & 20.65 \\
\hline 6 & 집 & 48.91 & 44 & 산 & 30.43 & 82 & 역 & 19.57 \\
\hline 7 & 슈퍼/슈퍼마켓 & 47.83 & 45 & 가격표 & 29.35 & 83 & 자리 & 19.57 \\
\hline 8 & 버스 & 46.74 & 46 & 간호사 & 29.35 & 84 & 포장 & 19.57 \\
\hline 9 & 아파트 & 46.74 & 47 & 입구 & 29.35 & 85 & 할인 & 19.57 \\
\hline 10 & 돈 & 46.74 & 48 & 정거장 & 28.26 & 86 & 도장 & 18.48 \\
\hline 11 & 우산 & 46.74 & 49 & 카드 & 28.26 & 87 & 상품권 & 18.48 \\
\hline 12 & 약 & 45.65 & 50 & 건강 & 27.17 & 88 & 황사 & 18.48 \\
\hline 13 & 가게 & 44.57 & 51 & 기침 & 27.17 & 89 & 교환 & 17.39 \\
\hline 14 & 미용실 & 44.57 & 52 & 바람 & 27.17 & 90 & 운행 & 17.39 \\
\hline 15 & 시장/마트 & 43.48 & 53 & 반찬 & 27.17 & 91 & 헌금 & 17.39 \\
\hline 16 & 엘리베이터 & 43.48 & 54 & 쇼핑 & 27.17 & 92 & 보험 & 16.30 \\
\hline 17 & 놀이터 & 40.22 & 55 & 우체국 & 27.17 & 93 & 숲 & 16.30 \\
\hline 18 & 치과 & 40.22 & 56 & 파마 & 26.09 & 94 & 승차 & 16.30 \\
\hline 19 & 의사 & 39.13 & 57 & 동전 & 26.09 & 95 & 우표 & 16.30 \\
\hline 20 & 비밀번호 & 39.13 & 58 & 벨 & 26.09 & 96 & 커트 & 16.30 \\
\hline 21 & 음료/음료수 & 39.13 & 59 & 접수 & 26.09 & 97 & 태풍 & 16.30 \\
\hline 22 & 음식점 & 39.13 & 60 & 커피 & 26.09 & 98 & 노선 & 15.22 \\
\hline 23 & 자전거 & 39.13 & 61 & 기분 & 25.00 & 99 & 세트 & 15.22 \\
\hline 24 & 지하철 & 38.04 & 62 & 기차 & 25.00 & 100 & 소포 & 15.22 \\
\hline 25 & 거스름돈 & 38.04 & 63 & 영수증 & 25.00 & 101 & 식품 & 15.22 \\
\hline 26 & 주차 & 36.96 & 64 & 매장 & 23.91 & 102 & 염색 & 15.22 \\
\hline 27 & 비 & 34.78 & 65 & 열차 & 23.91 & 103 & 왕복 & 15.22 \\
\hline 28 & 교회 & 33.70 & 66 & 요금 & 23.91 & 104 & 인출기 & 15.22 \\
\hline 29 & 주사 & 33.70 & 67 & 유치원 & 22.83 & 105 & 출금 & 15.22 \\
\hline 30 & 도서관 & 33.70 & 68 & 통증 & 21.74 & 106 & 편지 & 15.22 \\
\hline 31 & 층 & 33.70 & 69 & 바다 & 21.74 & 107 & 우체통 & 14.13 \\
\hline 32 & 치료 & 33.70 & 70 & 봉투 & 21.74 & 108 & 의류 & 14.13 \\
\hline 33 & 수영장 & 32.61 & 71 & 입금 & 21.74 & 109 & 신제품 & 11.96 \\
\hline 34 & 은행 & 32.61 & 72 & 지폐 & 21.74 & 110 & 잡화 & 11.96 \\
\hline 35 & 동물원 & 32.61 & 73 & 창구 & 21.74 & 111 & 인감 & 10.87 \\
\hline 36 & 장애인 & 32.61 & 74 & 열/발열 & 20.65 & 112 & 전 & 7.61 \\
\hline 37 & 에스컬레이터 & 31.52 & 75 & 표 & 20.65 & & & \\
\hline 38 & 택시 & 31.52 & 76 & 두통 & 20.65 & & & \\
\hline
\end{tabular}

(7) 그 밖의 제공서비스 $(N=20)$

\begin{tabular}{lcccccccc}
\hline$\#$ & 어휘 & 어휘공통성 백분율(\%) & $\#$ & 어휘 & 어휘공통성 백분율(\%) & $\#$ & 어휘 & 어휘공통성 백분율(\%) \\
\hline 1 & TV/텔레비전 & 78.26 & 9 & 위치/방향 & 56.52 & 17 & 인형 & 39.13 \\
2 & 과자/까까 & 73.91 & 10 & 공놀이 & 52.17 & 18 & 그림 & 34.78 \\
3 & 운동 & 69.57 & 11 & 장난감 & 52.17 & 19 & 불 & 34.78 \\
4 & 자동차 & 69.57 & 12 & 전화 & 52.17 & 20 & 비디오 & 17.39 \\
5 & 집 & 69.57 & 13 & 노래 & 47.83 & & & \\
6 & 친구 & 60.87 & 14 & 영화 & 47.83 & & \\
7 & 게임 & 60.87 & 15 & 책 & 47.83 & & \\
8 & 컴퓨터 & 56.52 & 16 & 채널 & 43.48 & & \\
\hline
\end{tabular}




\section{국문초록}

\section{장애인 활동지원서비스를 위한 $\mathrm{AAC}$ 부수어휘 조사}

\section{박다은 · 신상은}

충남대학교 대학원 언어병리학과

배경 및 목적: 장애인의 일상생활 수행을 돕는 장애인활동지원서비스에 대한 수요가 꾸준히 증가하고 있다. 복합적인 의사소통 요구 를 지닌 중증장애인이 보완대체의사소통(AAC)을 이용하여 활동지원사에게 효과적으로 자신의 필요와 요구를 전달할 수 있도록 하 기 위해 본 연구에서는 문헌에 기반하여 어휘에 대한 설문문항을 개발하고, 활동지원사들이 공통적으로 많이 필요로 하는 상황 별 부 수어휘 목록을 명사를 중심으로 구축하고자 하였다. 방법: 11 개의 문헌에서 보고하는 명사 어휘를 활동지원서비스의 영역별로 분류한 후, 체크리스트 형태의 설문지를 개발하여 105 명의 활동지원사를 대상으로 설문조사를 하였다. 응답에 대해서 각 어휘별 어휘공통성 백분율을 산출한 후 공통적으로 많이 요구하는 어휘를 분석하였다. 결과: $50 \%$ 이상의 어휘공통성을 보인 63 개의 명사가 활동지원서 비스 7 개 영역에서 확인된 244개의 부수어휘 목록에서 확보되었다. 244 개의 어휘는 외출 시 동행 영역에서 112 개, 청소 및 주변 정돈에 서 29 개, 개인위생관리에서 27 개, 취사 영역에서 26 개, 식사도움에서 20 개, 그 밖의 제공서비스 영역에서 20 개, 등하교 및 출퇴근 영역에 서 10 개의 어휘로 구성되어 있다. 논의 및 결론: 본 연구 결과는 활동지원서비스의 각 상황 별로 요구되는 주요 명사를 장애인의 AAC 도구에 반영하여 자신의 요구 사항을 활동지원사에게 적극적으로 표현하는 데 활용될 수 있을 것이다. 또한 서비스를 이용하지 않는 장애인이라 할지라도 일상생활에서 필요한 어휘를 제공하고 있기 때문에 그 활용도가 높을 것으로 기대한다.

핵심어: 보완대체의사소통, 부수어휘, 명사, 활동지원서비스, 어휘공통성

본 논문은 제1저자(박다은)의 석사학위논문의 일부를 수정 및 보완한 것임.

\section{참고문헌}

(*문헌분석에사용된 논문임)

김봉선 (2012). 장애인 활동보조 서비스 이용자의 '관계 맺기' 경험 과정 연구. 한국장애인 복지학, 18, 19-42.

김성희 (2014). 중증장애인의 활동지원서비스 이용 실태와 정책과제. 보건복지포럼, 217, 7-17.

*김수연, 김훈, 김종인 (2019). 시청각장애인의 의사소통을 위한 점어 및 점어기에 관한 기초 연구. 시각장애연구, 35(1), 19-39.

김영태, 박현주, 민홍기 (2003). 보완대체의사소통도구 개발을 위한 학령기 아동 및 성인의 핵심어휘 조사. 언어청각장애연구, 8(2), 93-110. *김정아, 연석정 (2019). 시설거주 지체장애인의 지역사회 적응활동을 활용한 AAC 중재 연구. 보완대체의사소통연구, 7(1), 153-171. 김종인, 한경임 (2016). 보완대체 의사소통 중재를 위한 일반유아와장애유아의 핵심어휘 연구. 특수아동교육연구, 18(2), 185-213. *문금현 (2011). 어휘장을 활용한 한국어 어휘 교육. 우리말교육현장연구, 5(2), 7-47. *문정연, 황보명 (2015). 의사소통장애 노인들을 위한 자신만만 보완대체의사소통(AAC)판 개발. 보완대체의사소통연구, 3(2), 139-152. *박승희 (1999). 정신지체 학생의 지역사회 기능에 필요한 기능적 어휘 목록 개발 연구. 재활복지, 3(1), 23-57. *박은혜 (1996). 보완.대체의사소통체계를 위한 기초어휘조사: 뇌성마비 초등 저학년 학생을 중심으로. 특수교육논총, 13(1), 91-115. 박혜연, 김영태 (2015). 그룹홈 거주 지적장애 성인의 핵심어휘 및 부수어휘 분석을 통한 의미적 언어사용 연구. 특수교육, 14(2), 81-103. *배소영, 곽금주 (2011). 한국판 맥아더 베이츠 의사소통발달평가(Korean version of M-B CDI: K M-B CDI). 서울. 마인드프레스. 보건복지부 (2019). 장애인과 함께 하는 활동지원사양성 교육과정. 세종: 보건복지부.

송재숙, 정종화 (2009). 중증장애인의 활동보조서비스 제공기관별 만족도 비교 연구. 한국장애인재활협회, 13(1), 187-213.

송혜정, 송양민, 박현주 (2015). 학령전기 아동의 내러티브 과제에서 나타나는 어휘사용 특성: AAC 적용을 위한 기초연구. Communication Sciences

\& Disorders, 20(3), 386-399. 
신상은 (2017). AAC 체계 구축을 위한 고빈도 용언의 기본형 분석. Communication Sciences \& Disorders, 22(1), 159-169.

신상은, 박다은 (2020). 아동과 성인의 AAC 핵심어휘 목록에 관한 국내 문헌고찰. 언어치료연구, 29(1), 71-83.

양희택 (2006). 장애인의 활동보조서비스 만족도에 영향을 미치는 요인에 관한 연구. 숭실대학교 대학원 박사학위논문.

오경아, 남경완, 김수진 (2014). 학령전기 아동의 자발화에 나타난 동사의 의미분류. 언어치료연구, 23(4), 63-72.

이영미, 김영태, 박은혜 (2005). 학령기 아동의 학교 상황 어휘 연구: AAC 적용을 위한 기초연구. 언어청각장애연구, 10(1), 134-152.

*이정은, 박은혜 (2000). 보완·대체의사소통체계 적용을 위한 상황 중심 핵심어휘 개발 연구. 재활복지, 4(1), 96-122.

*이진아, 편도원, 곽승철 (2011). 발달장애아동의 기초 학습어휘 선정에 관한 연구: 유치원 및 초등학교 아동을 중심으로. 특수교육학 연구, 46(2), 29-50.

임명순 (2018). 보완대체의사소통(AAC) 중재 서비스에 대한 뇌병변 성인의 요구분석. 가천대학교 대학원 석사학위논문.

전진아, 황수진 (2017). 자폐스펙트럼장애학생의 의사소통 어려움에 대한 장애인활동보조인의 인식 및 교육적 지원 요구. 자폐성장애연구, 17(3), 91-

114.

*장현진, 전희숙, 신명선, 김효정 (2013). 영·유아의 기초 어휘 선정연구. 언어치료연구, 22(3), 169-187.

정석희 (2018). 의사소통장애 및 언어치료에 대한장애인활동지원사들의 인식. 대구대학교 대학원 석사학위논문.

*지혜 (2018). 중증도에 따른 의사소통 상황 별 어휘: 실어증 입원 환자의 보호자 보고를 중심으로. 연세대학교 대학원 석사학위논문.

최복천, 김유리 (2016). 장애아동 부모가 인식하는 활동지원서비스의 문제점 및 개선방안에 관한 질적연구. 지체 · 중복· 건강 장애연구, 59(3), 207-

226.

황주희 (2014). 중증장애인 일상생활(24시간) 현황 및 과제. 보건복지포럼, 217, 18-28.

\section{ORCID}

박다은(제1저자, 대학원생 https://orcid.org/0000-0003-1391-4154); 신상은(교신저자, 교수 https://orcid.org/0000-0003-0148-7829) 